\title{
Dynamical insight into Caenorhabditis elegans eIF4E recognition specificity for mono-and trimethylated structures of mRNA 5' cap
}

\author{
Katarzyna Ruszczyńska-Bartnik • Maciej Maciejczyk • \\ Ryszard Stolarski
}

Received: 8 February 2010 /Accepted: 6 May 2010 /Published online: 10 June 2010

(C) The Author(s) 2010. This article is published with open access at Springerlink.com

\begin{abstract}
Specific recognition and binding of the ribonucleic acid $5^{\prime}$ termini (mRNA $5^{\prime}$ cap) by the eukaryotic translation initiation factor 4E (eIF4E) is a key, rate limiting step in translation initiation. Contrary to mammalian and yeast eIF4Es that discriminate in favor of 7-methylguanosine cap, three out of five eIF4E isoforms from the nematode Caenorhabditis elegans as well as eIF4Es from the parasites Schistosome mansoni and Ascaris suum, exhibit dual binding specificity for both 7-methylguanosine-and $\mathrm{N}^{2}, \mathrm{~N}^{2}, 7$-trimethylguanosine cap. To address the problem of the differences in the mechanism of the cap recognition by those highly homologic proteins, we carried out molecular dynamics simulations in water of three factors, IFE-3 and IFE-5 isoforms from C. elegans and murine eIF4E, in the apo form as well as in the complexes with 7-methyl-GDP and $\mathrm{N}^{2}$, $\mathrm{N}^{2}, 7$-trimethyl-GDP. The results clearly pointed to a dynamical mechanism of discrimination between each type of the cap, viz. differences in mobility of the loops located at the entrance into the protein binding pockets during the cap association and dissociation. Additionally, our data showed that the hydrogen bond involving the $\mathrm{N}^{2}$-amino group of 7-
\end{abstract}

K. Ruszczyńska-Bartnik · M. Maciejczyk

Nuclear Magnetic Resonance Laboratory, Institute of

Biochemistry and Biophysics, Polish Academy of Sciences,

02-106 Warsaw, Poland

\section{R. Stolarski $(\square)$}

Division of Biophysics, Institute of Experimental Physics,

Faculty of Physics, University of Warsaw,

02-089 Warsaw, Poland

e-mail: stolarsk@biogeo.uw.edu.pl

M. Maciejczyk

Department of Physics and Biophysics,

University of Warmia and Mazury,

Olsztyn 10-719, Poland methylguanosine and the carboxylate of glutamic acid was not stable. The dynamic mechanism proposed here differs from a typical, static one in that the differences in the protein-ligand binding specificity cannot be ascribed to formation and/or disruption of well defined stabilizing contacts.

Keywords Caenorhabditis elegans . Cap recognition . eIF4E isoforms · Molecular dynamics · mRNA 5' cap

\section{Introduction}

The $5^{\prime}$ terminal structure of eukaryotic RNA polymerase II transcripts (RNA $5^{\prime}$ cap) plays a crucial role in gene expression and regulation. The cap is specifically bound to several cellular and viral proteins, including various isoforms of eukaryotic translation factor eIF4E [1], nuclear cap-binding complex CBC [2], DcpS scavenger enzyme [3], poly(A) binding protein PABP [4], poly(A)-specific ribonuclease PARN [5], pokeweed antiviral protein PAP [6], cellular mRNA cap (guanine-N7) methyltransferase [7], human parneoplastic encephalomyeltis antigen $\mathrm{HuD}$ [8], vaccinia virus 2'-O-methyltransferase VP39 [9], influenza virus RNA polymerase [10], and dimethyltransferase TGS1 [11]. The eIF4E factors from vertebrates and yeast were shown to be highly selective for 7-methylguanosine cap (MMG-cap) [12], $\mathrm{m}^{7} \mathrm{GpppN}, \mathrm{N}=\mathrm{G}, \mathrm{A}, \mathrm{U}$ or $\mathrm{C}$. In the nematodes Caenorhabditis elegans and Ascaris suum as well as in the parasitic flatworm Schistosoma mansoni a high population of messenger ribonucleic acids (mRNAs) contain a hypermethylated cap form, $\mathrm{N}^{2}, \mathrm{~N}^{2}, 7$-trimethylguanosine cap (TMG-cap), $\mathrm{m}_{3}^{2,2,7} \mathrm{GpppN}$, which is acquired along with a spliced leader during trans-splicing of premRNA [13]. Affinity chromatography [14, 15], and 
fluorescence titration [16, 17] experiments showed that three out of five C. elegans eIF4E isoforms, IFE-1, IFE-2, IFE-5, are capable of binding specifically to the MMG-cap and to the TMG-cap. Two other isoforms, IFE-3, most similar to mammalian eIF4E, and IFE-4, related to the mammalian 4E-homologous protein 4E-HP, bind only to the MMG-cap. The dual binding specificity was also observed for eIF4Es from S. mansoni [18] and A. suum [19]. Values of the equilibrium dissociation constants, $K_{d}$, for some selected complexes of the dual specificity eIF4Es with typical MMG-cap and TMG-cap analogues are shown in Table 1 . The $\mathrm{K}_{\mathrm{d}}$ values for murine eIF4E are also shown for comparison. The values reported by various groups and derived by various titration methods, mainly fluorescence and isothermal calorimetry, can differ between each other. Nevertheless, the experimental data clearly show that both C. elegans IFE-3 and murine eIF4E strongly discriminate in favor of MMG-cap, ca. $11 \mathrm{~kJ} \mathrm{~mol}^{-1}$ and $16 \mathrm{~kJ} \mathrm{~mol}^{-1}$, respectively, while in the case of $C$. elegans IFE-5 the binding energies are similar. The energy difference between $S$. mansoni eIF4E complexes is ca. 5 to $7 \mathrm{~kJ} \mathrm{~mol}^{-1}$, depending on the titration experiment [18].

The TMG-cap occurs at the $5^{\prime}$ terminus of small nuclear RNA (snRNA), small nucleolar RNA (snoRNA) and in telomerase RNA TLC1 [11]. It is specifically recognized by Snurportin1 [20], a receptor for spliceosomal small nuclear particles (snRNPs).

As shown by X-ray crystallography [9, 12, 21-29] and multidimensional NMR [30] most of the cap-binding proteins converged at a common mechanism of the cap recognition via stacking of the 7-methylguanine moiety in between two aromatic amino acid side chains. The 7methylguanine base possesses a net positive charge, which seems indispensable for its proper recognition, i.e., the 7methylguanosine cannot be replaced by guanosine in the cap structure. In the snurportin1 complex with the dinucleotide TMG-cap analogue [20] the sandwich stacking

Table 1 Experimentally derived dissociation constants, $K_{d}[\mu \mathrm{M}]$, for the MMG-and TMG-cap analogues from $C$. elegans factors, IFE-3 and IFE-5, and $S$. mansoni eIF4E. The $\mathrm{K}_{\mathrm{d}}$ values for murine eIF4E are shown for comparison

\begin{tabular}{llll}
\hline & \multicolumn{2}{l}{$\mathrm{K}_{\mathrm{d}}[\mu \mathrm{M}]$} & \multirow{2}{*}{ Ref. No } \\
\cline { 2 - 3 } & $\mathrm{m}^{7} \mathrm{GTP}$ & $\mathrm{m}_{3}^{2,2,7} \mathrm{GTP}$ & \\
\hline eIF4E murine & 0.01 & 6.99 & {$[12]$} \\
IFE-3 C.elegans & 0.20 & 16.7 & {$[16]$} \\
IFE-5 C.elegans & 0.36 & 3.5 & {$[17]$} \\
& 0.14 & 0.33 & {$[16]$} \\
eIF4E S.mansoni & 0.54 & 0.92 & {$[17]$} \\
\hline
\end{tabular}

involves one tryptophan, and two bases of the cap, the first one, trimethylated, and the second one, unmethylated. In dimethyltransferase TGS1 the 7-methylguanine moiety is stacked only on one tryptophan and a serine polar side chain limits the binding pocket on the opposite side [11]. Except for the cation- $\pi$ stacking, the cap is also stabilized by a network of hydrogen bonds, direct or water mediated salt bridges, as well as less specific van der Waals and hydrophobic contacts. Only a few exceptions have been found yet where the recognition specificity is entirely mediated through hydrogen bonds and van der Waals contacts with 7-methylguanine, i.e., cap methyltransferase [7], and reovirus polymerase $\lambda 3$ [31].

In the mammalian, plant, and yeast eIF4E-cap complexes, two tryptophan aromatic residues take part in the sandwich cation- $\pi$ stacking with the 7-methylguanine moiety. Two hydrogen bonds involve $\mathrm{N} 1 \mathrm{H}$ and $\mathrm{N}^{2} \mathrm{H}$ atoms of 7-methylguanosine and the carboxyl group of a conserved glutamic acid, and one hydrogen bond is observed between $\mathrm{O}^{6}$ of $\mathrm{m}^{7} \mathrm{G}$ and the backbone amide nitrogen. Additional stabilizing interactions are between the phosphate chain of the cap and the arginine/lysine side chains of the protein. The first crystallographic structure of dual specificity eIF4E from Schistosoma mansoni in the complexes with two dinucleotide MMG-cap analogues [18] showed a similar binding mode as for the single specificity eIF4Es. The only difference seems to be in the conformation of E90 carboxylate of $S$. mansoni eIF4E that is rotated by $\sim 80^{\circ}$ in comparison to the orientation of the equivalent E103 [12, 23] in murine eIF4E. This precludes the formation of two strong hydrogen bonds with the 7methylguanine moiety. A similar rotation was also observed in the human eIF4E ternary complex with eIF4GI peptide and a glycerol molecule located in the cap-binding center [32]. Still, the contribution of that conformational change to MMG-cap vs. TMG-cap binding specificity remains unclear. The NMR analysis of the MMG-cap and TMG-cap complexes with $S$. mansoni eIF4E [18] showed substantial chemical shift perturbation for $c a$. 15 amino acids, most of them distributed around the cap-binding pocket. Based on the crystallographic and NMR data the authors suggested that intrinsic and specific conformational flexibility of the S. mansoni eIF4E plays a crucial role in the TMG-cap binding, analogous to an "induced fit" mechanism. On the contrary, combined mutagenesis studies and molecular dynamics simulations of $C$. elegans dual specificity IFE-5 led to a "structural" rather than a "dynamic" model. Larger width and depth of the cap-binding pocket was postulated to be responsible for the TMG-cap binding specificity [17]. Replacement of two amino acids, N64Y/V65L decreased the size of the pocket and gave rise to discrimination against TMG-cap by steric hindrance. However, it was noted that dual specific A. suum eIF4E does contain Y64 
<smiles></smiles>

b)<smiles>[2H]C1OC2c3nc(N(C)C)[nH]c(=O)c3[NH+](C)C2C(O)C1O</smiles>

Scheme 1 Chemical structures of the cap analogues. (a) $\mathrm{m}^{7} \mathrm{GDP}$, analogue of MMG-cap, (b) $\mathrm{m}_{3}{ }^{2,2,7} \mathrm{GDP}$, analogue of TMG-cap

and L65 residues [18]. Unfortunately, discrimination between TMG-cap and MMG-cap by snurportin1 is based on a mechanism that differs from that expected for the eIF4E factors $[20,33]$.

In order to get an insight into the mechanism of dual specificity in the cap recognition by some of highly homologic eIF4Es, we performed long-lasting molecular dynamics (MD) simulations in water for three selected eIF4E homologues, murine eIF4E as well as $C$. elegans IFE-3 and IFE-5, each of them in the apo form and in the complexes with $\mathrm{m}^{7} \mathrm{GDP}$ or with $\mathrm{m}_{3}{ }^{2,2,7} \mathrm{GDP}$ (Scheme 1). The results point to a dynamic mechanism of discrimination between the mono-and hypermethylated cap structures.

\section{Theory and methods}

Initial setup

The starting structure of the complex of truncated murine eIF4E(28-217) with $\mathrm{m}^{7}$ GDP for molecular dynamics simulations was taken from crystallography (PDB code: $1 \mathrm{EJ} 1$; [23]). The missing atoms of some of the amino acid side chains were completed by SCWRL [34]. The hydrogen atoms were added in Insight II (Accelrys Software Inc., U.S.A.). The starting structures of IFE isoforms were obtained by homology modeling with murine eIF4E(28217 ) bound to $\mathrm{m}^{7} \mathrm{GDP}$ as a template, with $51 \%$ and $42 \%$ sequence identity to IFE-3 and IFE-5, respectively. The multiple sequence alignment was performed by CLUSTAL $\mathrm{W}$ [35]. Ten structures for each isoform were obtained using the program MODELLER [36]. Additional harmonic constraints were introduced for the distances between the protein and the cap atoms that were engaged in hydrogen bonds, salt bridges and van der Waals contacts. Subsequently, the resulting structures were subjected to detailed analysis regarding packing of the residues, steric hindrance, and loop conformations. Based on the analysis one representative structure was chosen for each isoform. Due to high sequence homology the modeled IFE structures were very similar to that of the eIF4E template (Fig. 1), especially regarding the main polypeptide chains. The structures of the complexes of three $4 \mathrm{E}$ factors with $\mathrm{m}_{3}{ }^{2,2,7} \mathrm{GDP}$, and of murine eIF4E with GDP, were con-

a)

EIF4E_MOUSE IKHPLQNRWALWFFKNDKSKTWQANLRLISKFDTV IFE-5_CAEEL PIYPLQRNWSWWFLNDDRNASWQDRLKKVYTFNTV IFE-3_CAEEL TRHPLQNRWALWYLKADRNKEWEDCLKMVSLFDTV

EIF4E_MOUSE EDFWALYNHIQLSSNLMPGCDYSLFKDGIEPMWED IFE-5_CAEEL PEFWAFYEAILPPSGLNDLCDYNVFRDDIQPKWEA IFE-3_CAEEL EDFWSLYNHIQSAGGLNWGSDYYLFKEGIKPMWED

EIF4E_MOUSE EKNKRGGRWLITLNKQQRRSDLDRFWLETLLCLIG IFE-5 CAEEL PENWDGGRWLIIINKGKTPEVLDAVWLEILLALIG IFE-3_CAEEL VNNVQGGRWLVVVDKQRRTQLLDHYWLELLMAIVG

EIF4E MOUSE ESFDDYSDDVCGAVVNVRAKGDKIAIWTTECENRD IFE-5_CAEEL EQFGKDMESICGLVCNVRGQGSKISVWTKNCNDDD IFE-3_CAEEL EQFDEYGDYICGAVVNVRQKGDKVSLWTRDATRDD

EIF4E MOUSE AVTHIGRVYKERLGLPP-------KIVIGYQSHA IFE-5 CAEEL TNMRIGVVLKEKLMAAASKAHSKPLFDVIHYQTHR IFE-3_CAEEL VNLRIGQVLKQKLSIPD-------TEILRYEVHK

EIF4E MOUSE DTATKSGSTTKNRFVV IFE- 5 - CAEEL NCVKKTTSALKYKFSL IFE-3_CAEEL DSSARTSSTVKPRICL

b)

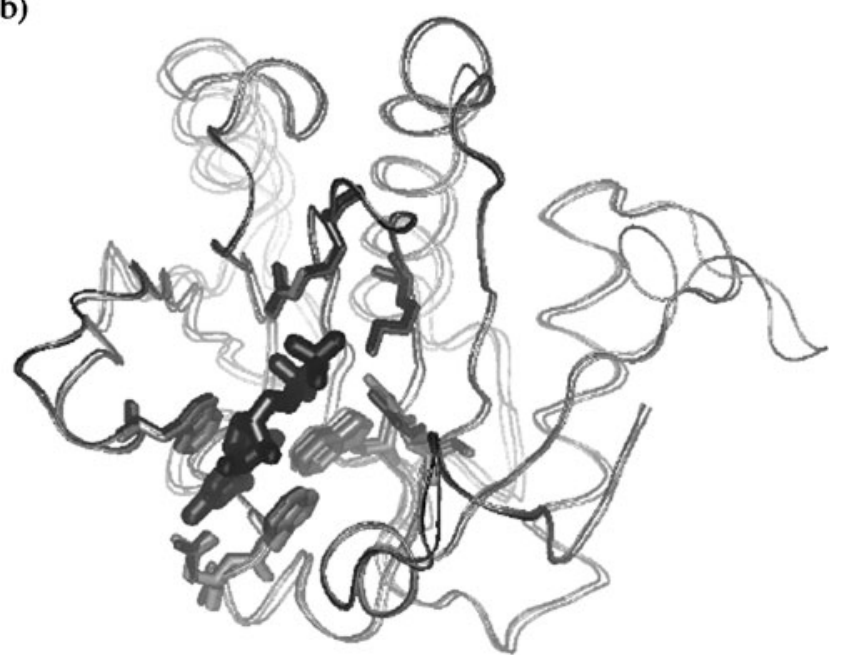

Fig. 1 Structural comparison of murine eIF4E(28-217) and its two $C$. elegans isoforms, IFE-3 and IFE-5. (a) Sequence alignment. (b) Superposition of the three protein complexes with $\mathrm{m}^{7}$ GDP. The cap and the amino acids engaged in its stabilizing are marked in bold 
structed by adding two methyl groups at $\mathrm{N}^{2}$ and by removing the methyl group from $\mathrm{N} 7$ in the protein$\mathrm{m}^{7}$ GDP complexes, respectively. The apo proteins were obtained by removing $\mathrm{m}^{7} \mathrm{GDP}$ from the complexes.

The ESP charges of the isolated ligands were calculated at $\mathrm{HF} / 6-31 \mathrm{G}(\mathrm{d}, \mathrm{p})$ level using Gaussian 94 (Gaussian Inc., Pittsburg PA, U.S.A.)

Molecular dynamics simulation and analysis

The MD simulations were carried out by the program Sigma [37] using CHARMM22 force field [38]. Each protein or complex was subjected to energy minimization without electrostatic interaction and immersed in an equilibrated TIP3P water box [39] keeping at least $10 \AA ̊$ shell thickness from the protein surface. The simulation procedure consisted of several equilibration MD runs preceded and followed by 500-step energy minimization, and a subsequent regular MD run, as follows. First, energy minimization and 48 ps dynamics of water molecules was performed keeping the protein or the complex immobilized. Second, energy minimization of the protein or of the complex with the water molecules kept fixed was followed by stepwise heating of the whole system from $50 \mathrm{~K}$ to $300 \mathrm{~K}$ for $82.56 \mathrm{ps}$. The initial velocities at each temperature were taken from Maxwell-Boltzmann distribution. The equilibration MD runs were performed in the $\mathrm{nVT}$ ensemble and the regular MD simulations were performed in the npT ensemble [40] at temperature $\mathrm{T}=$ $300 \mathrm{~K}$ and pressure $\mathrm{p}=1 \mathrm{~atm}$. The SHAKE algorithm [41] was applied to constrain the bonds. The electrostatic interactions were calculated by multiple time step [42] with a double cut-off at $6 \AA$ and $10 \AA$. Short-, middle-, and long range interactions, according to particle-mesh Ewald method [43, 44], were calculated for an integration timestep of 2, 4, and $12 \mathrm{fs}$, respectively. The simulations were run for $5 \mathrm{~ns}$ in the case of the apo proteins or for $10 \mathrm{~ns}$ in the case of the complexes, in order to reach at least partial equilibrium according to a stability criterion for the fluctuations of root-mean-square-deviation (RMSD) of the proteins' $\mathrm{C}_{\alpha}$ atoms.

The conformations of the solute on a simulated trajectory were written down every $0.96 \mathrm{ps}$ and analyzed regarding interatomic distances and torsion angles. Essential dynamics (ED) analysis of selected, equilibrium parts of the MD trajectories was performed according to Amadei et al. [45].

\section{Results}

An experimentally observed equilibrium association constant $\mathrm{K}_{\mathrm{as}}$ expressed in terms of the molar concentrations of the reactants in a protein-ligand association is related to the standard Gibbs free energy $\Delta \mathrm{G}^{\circ}$ of the association process at temperature $\mathrm{T}, \Delta \mathrm{G}^{\circ}=\mathrm{RT} \ln \mathrm{K}_{\mathrm{as}}$. Hence $\mathrm{K}_{\mathrm{as}}$ is a quantitative measure of the ligand affinity for the protein. Comparison of the $K_{a s}$ values for a series of structurally modified cap analogues enabled parsing of $\Delta G^{\circ}$ into separate contributions from various stabilizing contacts inside the eIF4E cap-binding pocket [12]. Bearing in mind an approximate character of the approach due to lack of additivity of the entropic terms [46, 47], combination of the crystallographic structure with such $\Delta \mathrm{G}^{\circ}$ analysis provided molecular mechanism of specific binding between the cap and eIF4E [12]. However, applying the procedure to detect the discrimination mechanism between MMG-and TMGcap by some eIF4Es $[17,18]$ has failed. The structures of IFE isoforms derived by homology modeling were very similar to that of the eIF4E template due to high sequence homology (Fig. 1). Therefore, the structural differences of potential importance for the MMG-vs. TMG-cap binding selectivity have not been identified. This prompted us to evaluate a discrimination mechanism of a dynamic type. The equilibrium association constant, $\mathrm{K}_{\mathrm{as}}=\mathrm{k}_{+1} / \mathrm{k}_{-1}$, depends on the ligand ability to form and leave the complex, expressed by kinetic rate constants $\mathrm{k}_{+1}$ and $\mathrm{k}_{-1}$, respectively. Higher $\mathrm{k}_{+1}$ and/or lower $\mathrm{k}_{-1}$ values give rise to an increase of $K_{a s}$. Since it was impossible to calculate theoretically the rate constants from all-atom MD simulations, we assumed that the MD analysis of the apo proteins provided some information on $\mathrm{k}_{+1}$ that reflects accessibility of the MMG-cap analogue and of the TMGcap analogue for the binding sites of the three eIF4Es. Similarly, the MD analysis of the three factors, each bound to either MMG-cap or TMG-cap, might provide some hints on the stability of the complexes that influences their dissociation kinetic constants $\mathrm{k}_{-1}$. It should be emphasized that the simulated apo structures were generated by removing the ligand, and therefore they differ from those derived experimentally, at least in the case of the NMR structure of murine apo-eIF4E [48]. The simulated apo structures may be regarded as those, which approximate final conformations the ligands would dock into, especially if the cap phosphate chain anchores first as postulated by a two-state model of the cap-binding [12] (see below). It is also worth noting, that the large structural fluctuations observed in the NMR structure of apo-eIF4E do not occur during our MD simulations.

The MD trajectories of the apo eIF4Es display enhanced flexibility of the loops around the entrance to the cap-binding pocket (Fig. 2), especially S1-S2 and S7S8 loops, while the secondary structure elements remained unchanged. This general view of the dynamic behavior is confirmed by the experimental data derived for the apo form of human eIF4E by multidimensional NMR [48], for the cap-free human eIF4E in the complex with glycerol 
a)

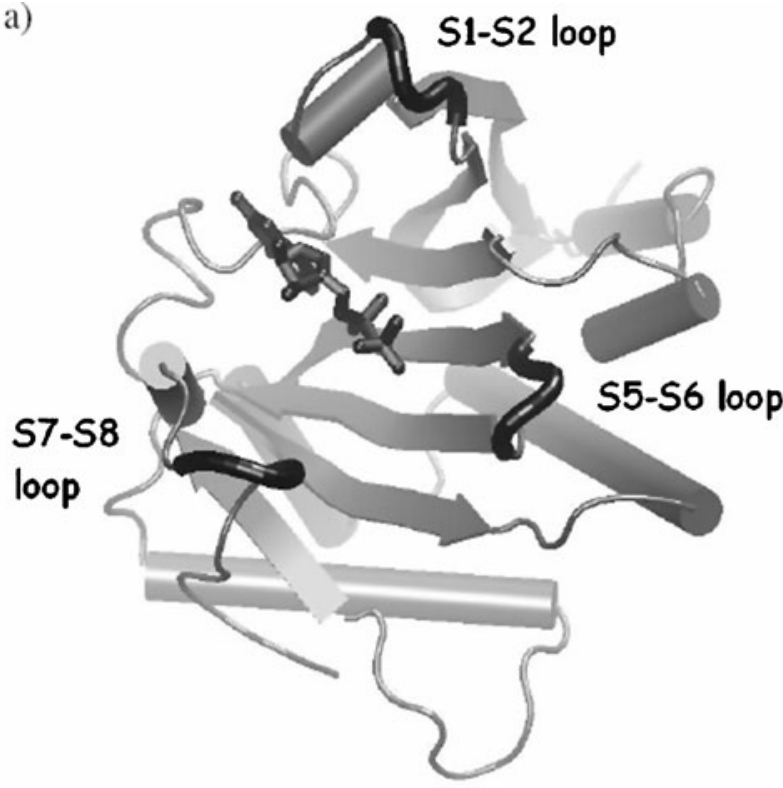

b)
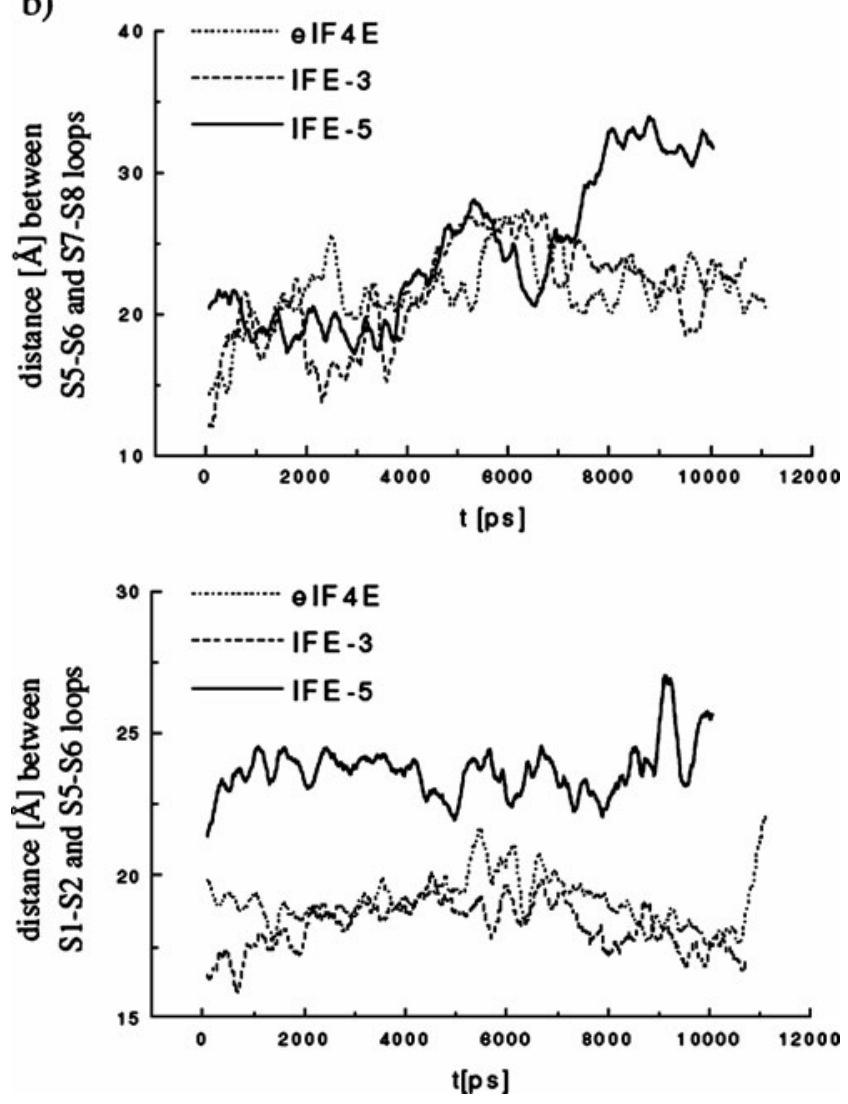

Fig. 2 Analysis of the cap accessibility into the binding pockets. (a) Location of the flexible loops in the eIF4E structure. (b) Time course of the distances between, (upper) S7-S8 and S5-S6 loops, measured for $\mathrm{C}_{\alpha}$ atoms of S209 and K159 for apo-eIF4E and apo-IFE-3, and for $\mathrm{C}_{\alpha}$ atoms of Q217 and K159 for apo-IFE-5, (lower) S5-S6 and S1-S2 loops, measured for $\mathrm{C}_{\alpha}$ atoms of $\mathrm{K} 159$ and R52. The lines are marked as follows: apo-eIF4E dotted, apo-IFE-3 dashed, apo-IFE-5 solid that seems to represent an intermediate state between the apo and the cap-bound form [32], and for the murine factor by hydrogen-deuterium exchange combined with electrospray mass spectrometry [49]. The secondary elements were preserved in apo eIF4E while the loops exhibited mobility on the ns-ps time scale that became abrogated upon the cap binding. The structural differences in the regions of loops S1-S2, S3-S4, S5-S6, and S7-S8 (Fig. 2a) resulted in the formation of the positively charged pocket to anchor the cap phosphate chain (loops S1-S2 and S7-S8), and the formation of the stacking triad and hydrogen bonding with the 7-methylguanine moiety via locking the W56 hinge (loop S1-S2) and rotating W102 (loop S3-S4) into the cap-binding site. The ability of W102 containing loop S3-S4 to rotate from the open (apo) state into the closed form was confirmed by both crystallography [32] and NMR studies [48]. Moreover, an alternative orientation of $\mathrm{W} 102$ indole ring was found by the diffraction studies of the eIF4E complexes with 7benzyl-GMP and 7-(p-fluorobenzyl)-GMP. The W102 residue flips through $180^{\circ}$ [50] in comparison with those complexes which contain the 7-methylguanosine caps [12, $23,24]$. All those observations agree with the two-state model of the cap-binding [12], in which anchoring of the phosphate chain was followed by a cooperative formation of the stacking triad and hydrogen bonds. This model, derived from analysis of the fluorescence titration of eIF4E with structurally modified cap analogues, was confirmed by kinetic stopped flow experiments [51, 52]. Contrary to our analysis, Slepenkov et al. [53] performed and analyzed the stopped flow experiments differently, and postulated a one-step mechanism. However, our results are confirmed not only by the standard analysis of the stop-flowed kinetic traces under pseudo first-order conditions [51] but also by running the experiments under the second-order conditions combined with numerical integration of the suitable differential kinetic equations [52] by the state-of-the-art program DynaFit [54].

The flexibility of the loops seem to be crucial for the discrimination between $\mathrm{m}^{7}$ GDP and $\mathrm{m}_{3}{ }^{2,2,7}$ GDP by murine eIF4E and $C$. elegans IFE-3 and IFE-5. The calculated distances between S7-S8 and S5-S6, and between S5-S6 and $\mathrm{S} 1-\mathrm{S} 2$, on the final parts of the MD trajectories (Fig. $2 b$ ) are $c a .10 \AA$ greater for IFE-5 that binds the TMGcap than for IFE-3 and murine eIF4E that are specific for the MMG-cap only. Hence, the TMG-analogue with two additional methyl groups can easy penetrate the IFE-5 binding pocket contrary to other factors.

A similar analysis of the dynamics of the protein-cap complexes shows stable contacts between the cap phosphates and the arginine/lysine side chains, irrespective of the bound analogue. This is consistent with the anchoring character of the phosphate groups in the cap stabilization 


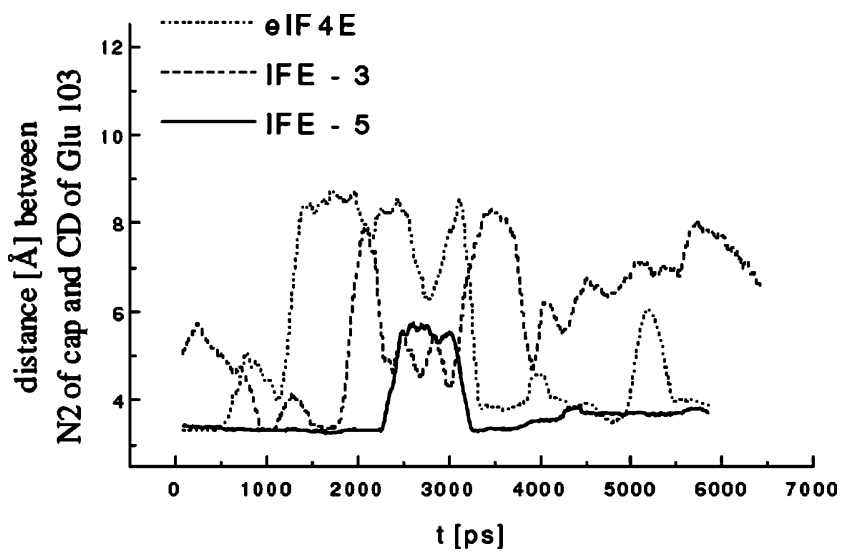

Fig. 3 Time dependence of the distance (in $\AA$ ) between $\mathrm{N}^{2}$ of $\mathrm{m}^{7} \mathrm{GDP}$ and Glu103 side chain carboxyl in murine eIF4E (dotted), IFE-3 (dashed), and IFE-5 (solid)

inside the eIF4E binding slot [12]. On the contrary, the mutual orientations of the rings in the cation- $\pi$ stacking triad undergo larger fluctuations in respect to the starting structure. As expected, the largest changes are observed in the eIF4E-GDP complex that is stabilized by weaker $\pi-\pi$ stacking, i.e., a perpendicular orientation of the W56 and G rings and a shift of W102 deeper into the binding pocket. In the case of all the other complexes the stacking triad is kept principally unchanged, with relatively larger fluctuations of $\mathrm{W} 102$. A temporary increase of the distance between W102 and $\mathrm{m}^{7} \mathrm{G}$ rings are observed in the eIF4E- $\mathrm{m}_{3}^{2,2,7} \mathrm{GDP}$ and IFE- $3-\mathrm{m}_{3}{ }^{2,2,7} \mathrm{GDP}$, but not in IFE-5- $\mathrm{m}_{3}{ }^{2,2,7} \mathrm{GDP}$, complexes. On the other hand, the hydrogen bond between the $\mathrm{N}^{2}$-amino group of $\mathrm{m}^{7} \mathrm{G}$ and the E103 carboxylate (Fig. 3) is being broken and reformed due to shifts of the E103 side chain into the bulk solvent. Inherent "plasticity" of that part of the cap-binding center, resulting in a rotation of E103 side chain and a movement of W102 side chain, was also observed in the cap-free eIF4E ternary complex with eIF4GI peptide and glycerol in the cap-binding pocket [32]. Therefore, the low affinity of the TMG-cap for murine eIF4E cannot be explained by lack of that hydrogen bond due to the hypermethylation.

The distance between loops S7-S8 and S5-S6 in the eIF4E-cap complexes (Fig. 4) is shown to correlate with the affinity of various cap types for the eIF4E isoforms. Binding of $\mathrm{m}^{7} \mathrm{GDP}$ to murine eIF4E results in bend of S7-S8 toward S5-S6 that might help to keep the ligand in the binding centre by water mediated interaction between K159 and, e.g., S209. As shown previously [55] K159 is very important for binding the capped mRNA. Closing the entrance to the capbinding pocket by decreasing the distance between S209 and K159 was also observed in MD simulations of phosphorylated eIF4E [25]. In the complexes with the low affinity ligands, $\mathrm{m}_{3}{ }^{2,2,7} \mathrm{GDP}$ and GDP, the distance between the loops is larger, thus making it easier for those ligands to leave the complexes. Similarly, the distance between the loops in the IFE-3 complex with $\mathrm{m}^{7} \mathrm{GDP}$ is much smaller than in the IFE-3 complex with $\mathrm{m}_{3}{ }^{2,2,7} \mathrm{GDP}$, while for both IFE- 5 complexes it is kept fairly large, irrespective of the ligand. The analysis of the overall dynamics of the capbound eIF4E isoforms was also carried out by ED analysis of the covariance matrix of the atomic displacements [45]. The scalar products of the the vectors representing the normalized $\mathrm{C}_{\alpha}$ displacements and the eigenvectors corresponding to the largest eigenvalue $(\lambda=1)$ show nonGaussian distributions with 2-3 maxima. This can be interpreted as correlated, long-range movements, in which the loops oscillate around several mean positions (Fig. 5). The histograms for the scalar products of the eigenvectors corresponding to lower eigenvalues $(\lambda=10)$ are Gaussian, as expected for equilibrated, independent and harmonic motions.
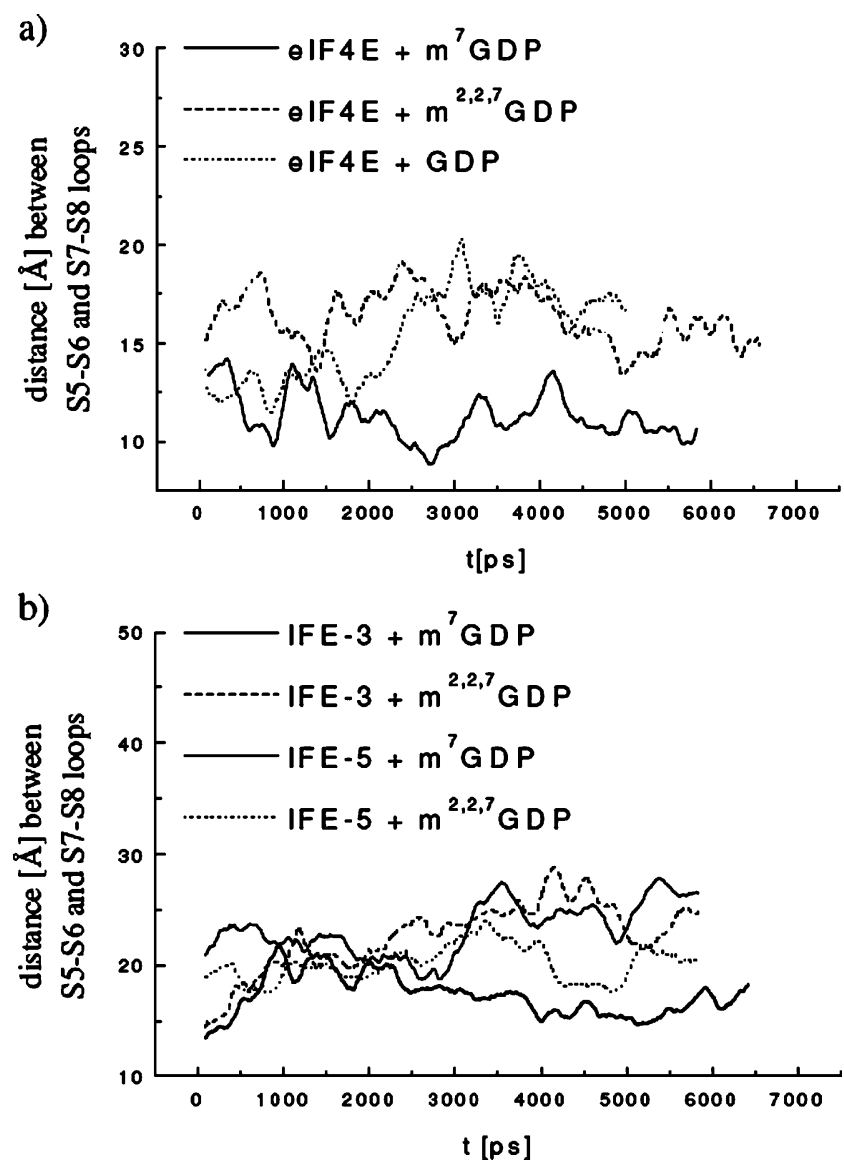

Fig. 4 Analysis of the cap propensity to leave the cap-binding pocket. Time course of the distances between S7-S8 and S5-S6 loops, measured for $\mathrm{C}_{\alpha}$ atoms of S209 and K159 (IFE-3, eIF4E), and for $\mathrm{C}_{\alpha}$ atoms of Q217 and K159 (IFE-5). (a) Murine eIF4E bound to $\mathrm{m}^{7} \mathrm{GDP}$ (solid), to $\mathrm{m}_{3}^{2,2,7} \mathrm{GDP}$ (dashed), and to GDP (dotted). (b) IFE-3 bound to $\mathrm{m}^{7} \mathrm{GDP}$ (solid bold) and to $\mathrm{m}_{3}^{2,2,7} \mathrm{GDP}$ (dashed), and IFE-5 bound to $\mathrm{m}^{7} \mathrm{GDP}$ (solid) and to $\mathrm{m}_{3}{ }^{2,2,7} \mathrm{GDP}$ (dotted) 


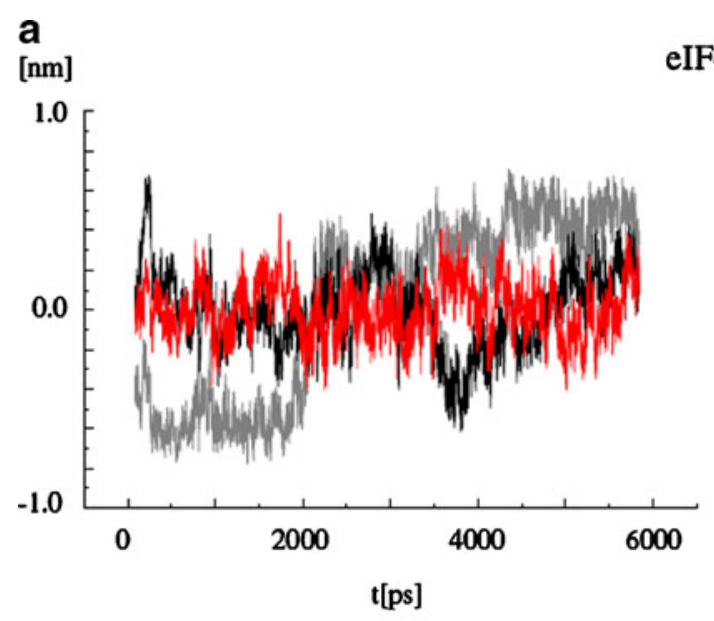

$\mathrm{eIF} 4 \mathrm{E}+\mathrm{m}^{7} \mathrm{GDP}$
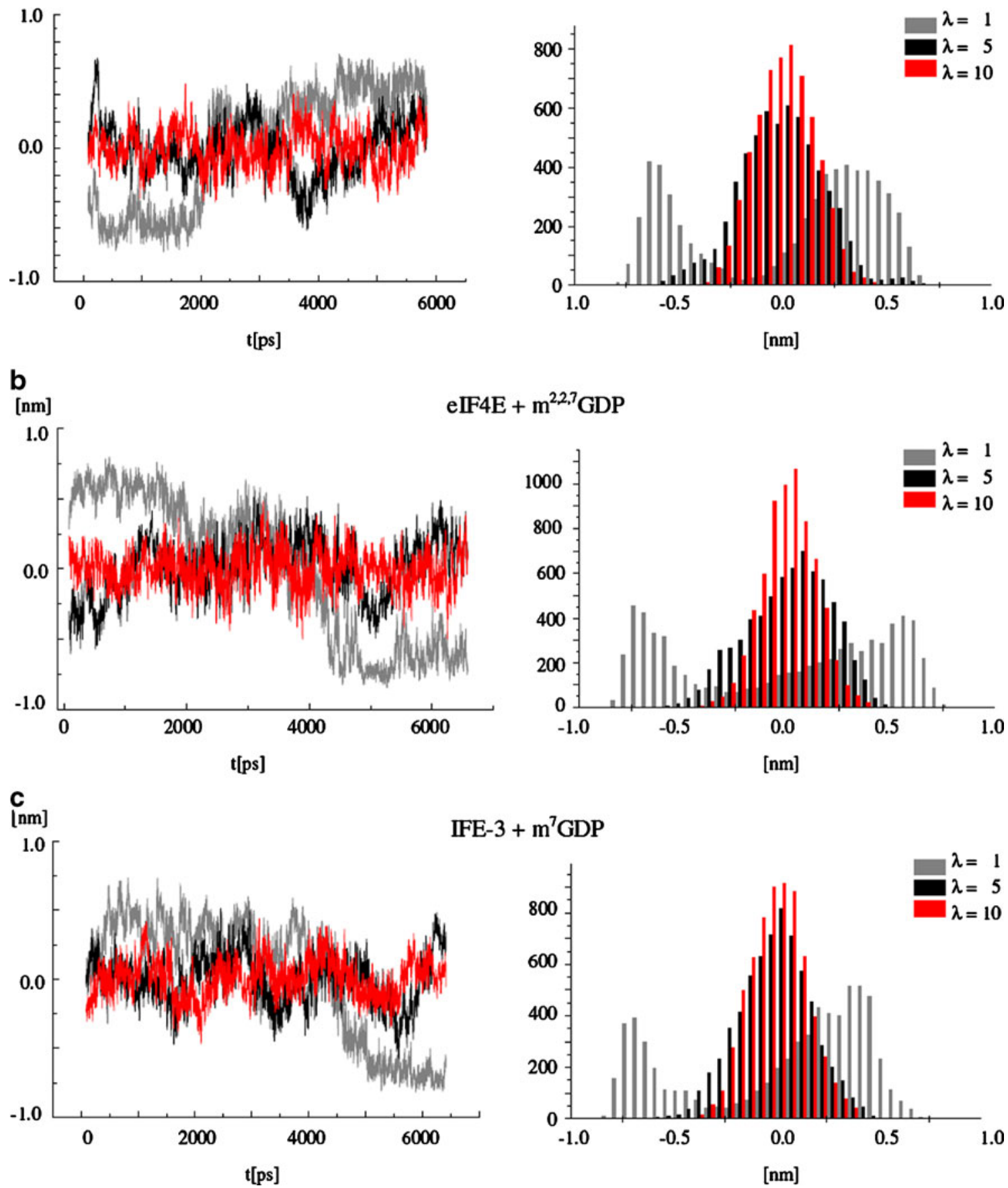

Fig. 5 Mobility of the apo-and cap-bound eIF4Es by essential dynamics analysis. Motions along the first $(\lambda=1)$, fifth $(\lambda=5)$, and tenth $(\lambda=10)$ eigenvectors obtained from the $C_{\alpha}$ coordinates covariance matrix, and the corresponding probability distribution

\section{Discussion}

The knowledge of the molecular basis of the RNA 5' cap structure recognition by the cap-binding proteins is a prerequisite for understanding possible mechanisms of

the cap functioning in various types of the gene expression processes in eukaryotes, such as translation initiation, mRNA splicing, and export of RNAs to the cytoplasm. It seems that various evolutionary unrelated cap-binding proteins converged on a similar general

for the displacements (nm), (a) eIF4E bound to $\mathrm{m}^{7} \mathrm{GDP}$, (b) eIF4E bound to $\mathrm{m}_{3}^{2,2,7} \mathrm{GDP}$, (c) IFE-3 bound to $\mathrm{m}^{7} \mathrm{GDP}$, (d) IFE-3 bound to $\mathrm{m}_{3}^{2,2,7} \mathrm{GDP}$, (e) IFE-5 bound to $\mathrm{m}^{7} \mathrm{GDP}$, (f) IFE-5 bound to $\mathrm{m}_{3}{ }^{2,2,7} \mathrm{GDP}$ 

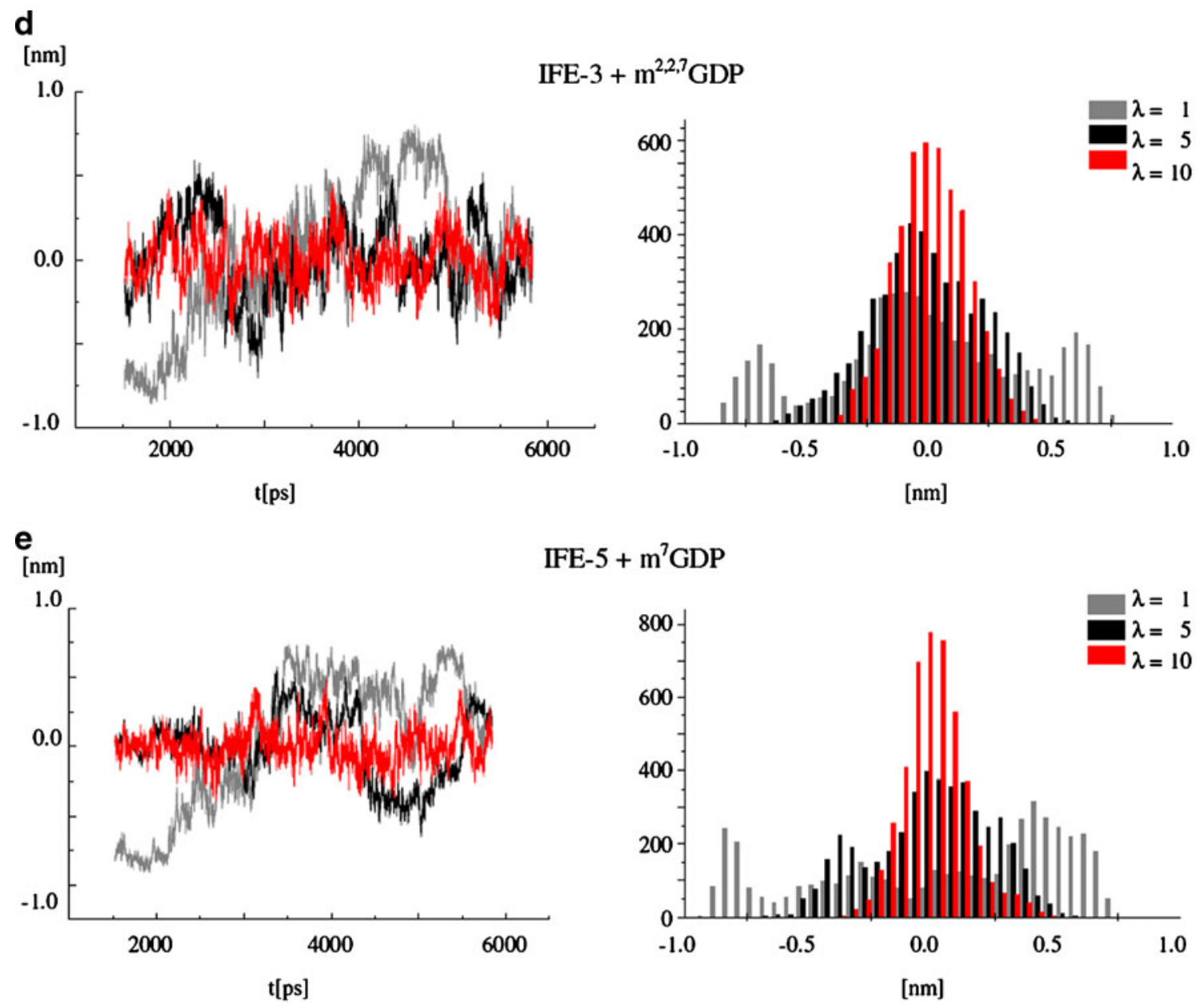

IFE-5 $+m^{7}$ GDP
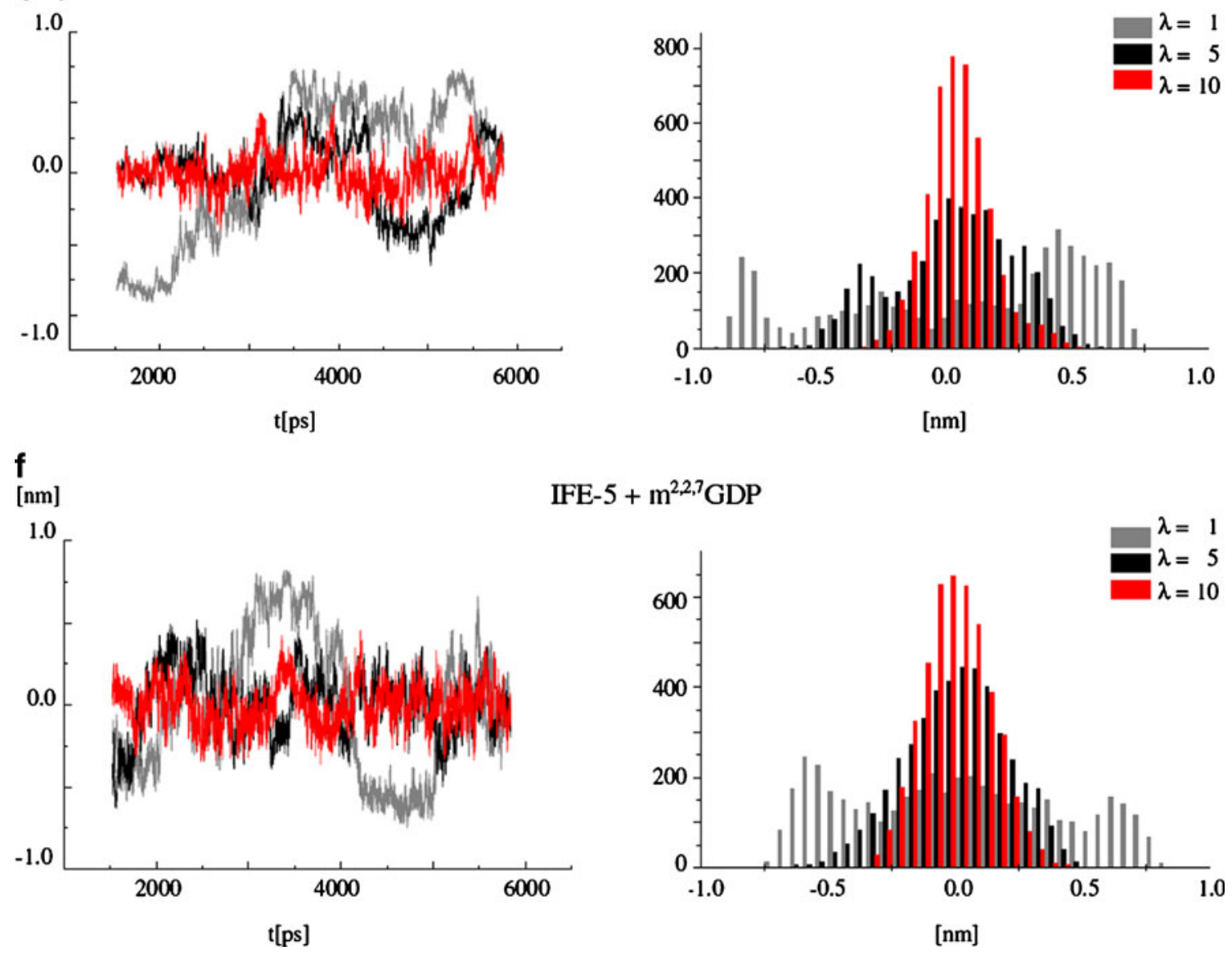

Fig. 5 (continued)

mechanism of the cap recognition. Subtle modifications of the general recognition mechanism of the cap may lead to differences in the protein functions, e.g., the diverse role of two aromatic amino acids that stack with the 7-methylguanosine moiety [56-58]. The methyl group at N7 in the cap structure imparts a net positive charge to the guanine ring, and results in more efficient stacking compared with the unmethylated base. Quantum mechanical calculations showed that a typical energy of the cation- $\pi$ stacking of the $m^{7} G$ base in the complex with the tyrosine or tryptophan aromatic ring is in a range $-11.4 \mathrm{kcal} \mathrm{mol}^{-1}$ to $-16.23 \mathrm{kcal} \mathrm{mol}^{-1}$, while the $\mathrm{G} / \mathrm{Y} \pi$ $\pi$ stacking energy is ca. $-6 \mathrm{kcal} \mathrm{mol}^{-1}$ [59]. Additional methyl groups at $\mathrm{N}^{2}$ do not change the stacking ability of 
the cap. The stacking energy of $\mathrm{m}_{3}{ }^{2,2,7} \mathrm{G} / \mathrm{W} 276$ in Snurportin $1,-12.52 \mathrm{kcal} \mathrm{mol}^{-1}$, is close to typical values obtained for the $\mathrm{m}^{7} \mathrm{G} / \mathrm{W}$ complexes.

The presence of two methyl substituents in the amino group of 7-methylguanosine brakes at least one stabilizing hydrogen bond in the cap-binding protein pockets and may lead to a substantial decrease of the association constants observed for the complexes with TMG-cap. On the other hand, the dual specificity cap-binding proteins possess high homology and structure similarity to those that discriminate between the MMG-cap and the TMG-cap. Hence, it is a great challenge to conceive a molecular model of the discrimination vs. dual specificity for the protein-cap association. The explanations usually do not go beyond formulations like "the differences in the size of the capbinding pocket in the C. elegans isoforms of eIF4E" [20]. Our approach to elucidate the specificity of the caps recognition can be expressed in terms of the ligand ability to enter or leave the apo protein binding pocket, since the equilibrium association constant is determined by the ratio of the two rate constants. Although we were not able to calculate the values of the rate constants by all-atom MD simulations, the comparative analysis of the MD trajectories of the apo- and cap-bound factors provides a more detailed explanation for the differences in the binding specificity of two C. elegans eIF4E isoforms, IFE-3 and IFE-5, than those published hitherto. The dynamic mechanism of the discrimination between two types of the cap may be ascribed to differences in mobility of the loops around the entrance to the protein cap-binding pockets, especially S7S8 loop. Our results show also higher rigidity of the cation$\pi$ stacking triad and of the stabilizing interactions (salt bridges, hydrogen bonds) involving the cap phosphate chain compared with a more flexible character of the hydrogen bonds. The results of our computer modeling are generally consistent with the experimental, structural and dynamic, data $[32,48,49]$.

\section{Conclusions}

Discrimination between two types of the cap, MMG-cap and TMG-cap, consist neither in the differences in the stacking energy nor in well-defined structural differences inside the cap-binding pocket. Both 7-methylguanosine and its hypermethylated form were found to stack equally well in between two amino acid aromatic rings [59], and the structure of $S$. mansoni eIF4E in complex with the MMGcap analogues [18], showed a very similar mode of binding to that of the single specificity eIF4Es. MD simulations based on the known structures of the cap-eIF4E complexes provided means to evaluate the discrimination mechanism. Contrary to the comparative analysis of the "static" net of stabilizing contacts inside the cap-binding pockets of highly homologic eIF4Es, we took into account the differences in the dynamics of the formation and dissociation of the eIF4E-cap complexes. An exact specification of the role of particular amino acids in the proposed dynamical mechanism, e.g., their mutual interactions and/or their interactions with various cap structures, needs further investigation.

Acknowledgments This work was supported by the Polish Ministry of Science and Higher Education, grant Nos. N N301 035 936, N N301 267137 and BST-1434/BF. The MD simulations were performed in the Interdisciplinary Centre for Mathematical and Computational Modelling (ICM) at the University of Warsaw. We are indebted to Dr. Joanna Trylska for critical reading of the manuscript.

Open Access This article is distributed under the terms of the Creative Commons Attribution Noncommercial License which permits any noncommercial use, distribution, and reproduction in any medium, provided the original author(s) and source are credited.

\section{References}

1. Joshi B, Cameron A, Jagus R (2004) Characterisation of mammalian eIF4E-famili members. Eur J Biochem 271:21892203

2. Lewis JD, Izaurralde E (1997) The role of the cap structure in RNA processing and nuclear export. Eur J Biochem 247:461-469

3. Liu H, Rodgers ND, Jiao X, Kiledijian M (2002) The scavenger mRNA decapping enzyme DcpS is a member of the HIT family of pyrophosphates. EMBO J 21:4699-4708

4. Kühn U, Wahle E (2004) Structure and function of poly(A) binding proteins. Biochim Biophys Acta 1678:67-84

5. Martinez J, Ren Y-G, Thuresson A-C, Hellman U, Åström J, Virtanen A (2000) A 54-kDa fragment of the poly(A)-specific ribonuclease is oligomeric, processive, and cap-interacting poly (A)-specific 3' exonuclease. J Biol Chem 275:24222-24230

6. Hudak KA, Bauman JD, Tumer NE (2002) Pokeweed antiviral protein binds to the cap structure of eukaryotic mRNA and depurinates the mRNA downstream of the cap. RNA 8:1148-1159

7. Fabrega C, Hausmann S, Shen V, Shuman S, Lima CD (2004) Structure and mechanism of mRNA cap (Guanine-N7) methyltransferase. Mol Cell 13:77-89

8. Wang X, Hall TMT (2001) Structural basis for recognition of AU-rich element RNA by the HuD protein. Nat Struct Biol $8: 141-145$

9. Hodel AE, Gershon PD, Shi X, Wang S-M, Quiocho FA (1997) Specific protein recognition of an mRNA cap through its alkylated base. Nat Struct Biol 4:350-354

10. Guilligay D, Tarendeau F, Resa-Infante P, Coloma R, Crepin T, Sehr P, Lewis J, Ruigrok RW, Ortin J, Hart DJ, Cusack S (2008) The structural basis for cap binding by influenza virus polymerase subunit PB2. Nat Struct Mol Biol 15:500-506

11. Monecke T, Dickmanns A, Ficner R (2009) Structural basis for $\mathrm{m}^{7} \mathrm{G}$-cap hypermethylation of small nuclear, small nucleolar and telomerase RNA by the dimethyltransferase TGS1. Nucleic Acids Res 37:3865-3877

12. Niedzwiecka A, Marcotrigiano J, Stepinski J, Jankowska-Anyszka M, Wyslouch-Cieszynska A, Dadlez M, Gingras A-C, Mak P, Darzynkiewicz E, Sonenberg N, Burley SK, Stolarski R (2002) Biophysical studies of eIF4E cap-binding protein: recognition of mRNA 5 ' cap structure and synthetic fragments of eIF4G and 4EBP1 proteins. J Mol Biol 319:615-635 
13. Blumenthal T (1998) Gene clusters and polycistronic transcription in eukaryotes. BioEssays 20:480-487

14. Jankowska-Anyszka M, Lamphear BJ, Aamodt EJ, Harrington T, Darzynkiewicz E, Stolarski R, Rhoads RE (1998) Multiple isoforms of eukaryotic protein syntesis initiation factor $4 \mathrm{E}$ in Caenorhabditis elegans can distinguish between mono-and trimethylated mRNA cap structures. J Biol Chem 273:10538-10542

15. Keiper BD, Lamphear BJ, Desphande AM, Jankowska-Anyszka M, Aamodt EJ, Blumenthal T, Rhoads RE (2000) Functional characterization of five eIF4E isoforms in Caenorhabditis elegans. J Biol Chem 275:10590-10596

16. Stachelska A, Wieczorek Z, Ruszczynska K, Stolarski R, Pietrzak M, Lamphear BJ, Rhoads RE, Darzynkiewicz E, JankowskaAnyszka M (2002) Interaction of three Caenorhabditis elegans isoforms of translation initiation factor eIF4E with mono-and trimethylated mRNA 5' cap analogues. Acta Biochim Pol 49:671682

17. Miyoshi H, Dwyer DS, Keiper BD, Jankowska-Anyszka M, Darzynkiewicz E, Rhoads RE (2002) Discrimination between mono-and trimethylated cap structures by two isoforms of Caenorhabditis elegans eIF4E. EMBO J 21:4680-4690

18. Liu W, Zhao R, McFarland C, Kieft J, Niedzwiecka A, JankowskaAnyszka M, Stepinski J, Darzynkiewicz E, Jones DNM, Davis RE (2009) Structural insight into parasite eIF4E binding specificity for $\mathrm{m} 7 \mathrm{G}$ and $\mathrm{m} 2,2$, 7G mRNA cap. J Biol Chem 284:31336-31349

19. Lall S, Friedman CC, Jankowska-Anyszka M, Stepinski J, Darzynkiewicz, Davis RE (2004) Contribution of trans-splicing, 5'-leader length, cap-poly(A) synergism, and initiation factors to nematode translation in an Ascaris suum embryo cell-free system. J Biol Chem 279:45573-45585

20. Strasser A, Dickmanns A, Luehrmann R, Ficner R (2005) Structural basis for $\mathrm{m}(3) \mathrm{G}$-cap-mediated nuclear import of spliceosomal UsnRNPs by snurportin1. EMBO J 24:2235-2243

21. Mazza C, Segref A, Mattaj IW, Cusack S (2002) Large-scale induced fit recognition of an $\mathrm{m} 7 \mathrm{G}$ pppG cap analogue by the human nuclear cap-binding complex. EMBO J 21:5548-5557

22. Calero G, Wilson K, Ly T, Rios-Steiner JR, Clardy J, Cerione RA (2002) Structural basis of $\mathrm{m}(7) \mathrm{GpppG}$ binding to the nuclear capbinding protein complex. Nat Struct Biol 9:912-917

23. Marcotrigiano J, Gingras AC, Sonenberg N, Burley SK (1997) Cocrystal structure of the messenger RNA $5^{\prime}$ cap-binding protein (eIF4E) bound to 7-methyl-GDP. Cell 89:951-961

24. Tomoo K, Shen X, Okabe K, Nozoe Y, Fukuhara S, Morino S, Ishida T, Taniguchi T, Hasegawa H, Terashima A, Sasaki M, Katsuya Y, Kitamura K, Miyoshi H, Ishikawa M, Miura K (2002) Crystal structures of 7-methylguanosine $5^{\prime}$-triphosphate $(\mathrm{m}(7)$ GTP)-and P(1)-7-methylguanosine-P(3)-adenosine-5'，5'-triphosphate $(\mathrm{m}(7) \mathrm{GpppA})$-bound human full-length eukaryotic initiation factor 4E: biological importance of the $\mathrm{C}$-terminal flexible region. Biochem J 362:539-544

25. Tomoo K, Shen X, Okabe K, Nozoe Y, Fukuhara S, Morino S, Sasaki M, Taniguchi T, Miyagawa H, Kitamura K, Miura K, Ishida T (2003) Structural features of human initiation factor 4E, studied by X-ray crystal analysis, and molecular dynamics simulations. J Mol Biol 328:365-383

26. Gu M, Fabrega C, Liu SW, Liu H, Kiledjian M, Lima CD (2004) Insights into the structure, mechanism, and regulation of scavenger mRNA decapping activity. Mol Cell 14:67-80

27. Chen N, Walsh MA, Liu Y, Parker R, Song H (2005) Crystal Structures of human DcpS in ligand-free and m7GDP-bound forms suggest a dynamic mechanism for scavenger mRNA decapping. J Mol Biol 347:707-718

28. Fechter P, Mingay L, Sharps J, Chambers A, Fodor E, Brownlee GG (2003) Two aromatic residues in the PB2 subunit of influenza A RNA polymerase are crucial for cap binding. J Biol Chem 278:20381-20388
29. Monzingo Af, Dhaliwal S, Dutt-Chaudhuri A, Lyon A, Sadow JH, Hoffman DW, Robertus JD, Browning KS (2007) The structure of the translation initiation factor eIF4E from wheat reveals a novel disulfide bond. Plant Physiol 143:1504-1518

30. Matsuo H, Li H, McGuire AM, Fletcher CM, Gingras A-C, Sonenberg N, Wagner G (1997) Structure of translation factor eIF4E bound to $\mathrm{m}^{7} \mathrm{GDP}$ and interaction with 4E-binding protein. Nat Struct Biol 4:717-724

31. Tao Y, Farsetta DL, Nibert M, Harrison SC (2002) RNA Synthesis in a cage-structural studies of reovirus polymerase $\lambda 3$. Cell 111:733-745

32. Brown CJ, Verma CS, Walkinshaw MD, Lane DP (2009) Crystallization of eIF4E complexed with eIF4GI peptide and grycerol reveals distinct structural differences around the capbinding site. Cell Cycle 8:1905-1911

33. Goette M, Stumpe MC, Ficner R, Grubmüller H (2009) Molecular determinants of snurportin 1 ligand afinity and structural response upon binding. Biophys J 97:581-589

34. Brower MJ, Cohen EF, Dunbrack RL (1997) Prediction of protein side-chains rotamers from backbone dependent rotamer library: a new homology modeling tool. J Mol Biol 267:1268-1282

35. Thompson JD, Higgins DG, Gibson TJ (1994) CLUSTAL W: improving the sensitivity of progressive multiple sequence alignment through sequence weighting, position-specific gap penalties and weight matrix choise. Nucleic Acids Res 22:46734680

36. Sali A, Blundell TL (1993) Comparative protein modelling by satisfaction of spatial restraints. J Mol Biol 234:779-815

37. Mann G, Yun RH, Nyland L, Prins J, Board J, Hermans J (2002) Sigma MD program and a generic interface applicable to multifunctional programs with complex, hierarchical command structure. In: Schlick T, Gan HH (eds) Computational methods for macromoleules: challenges and applications. Springer, Berlin, pp $129-145$

38. Mac Kerell Jr AD, Bashford D, Bellot M et al (1998) All-atom empirical potential for molecular modeling and dynamics studies of ptoteins. J Phys Chem 102:3586-3616

39. Jorgensen W, Chandrasekhar J, Madura J, Impey R, Klein M (1983) Comparison of simple potential function for simulating liquid water. J Chem Phys 79:926-936

40. Berendsen HJC, Postma JCM, van Gunsteren WE, Di Nola A, Haak JR (1984) Molecular dynamics with coupling to an external bath. J Chem Phys 81:3684-3690

41. Ryckaert JP, Cicciotti G, Berebdsen HJC (1977) Numerical integration of the Cartesian equations of mosion of a system with constraints: molecular dynamics of n-alkanes. J Comput Phys 23:327-341

42. Tuckreman NE, Berne BJ, Martyna GJ (1992) Reversible multiple time scale molecular dynamics. J Chem Phys 97:1990-2001

43. Darden TA, York DM, Pedersen LG (1993) Particle mesh Ewald: an $\mathrm{N} \log (\mathrm{N})$ method for Ewald sums in large systems. J Chem Phys 98:10089-10092

44. Schlick T, Skeel R, Brünger A, Kale L, Board JA, Hermans J, Schulten K (1999) Algorithmic challanges in computational molecular biophysics. J Comput Phys 151:9-48

45. Amadei A, Linssen ABM, Berendsen HJC (1993) Essential dynamics of proteins. Proteins Struct Funct Bioinf 17:412-425

46. Mark AE, van Gunsteren WF (1994) Decomposition of the free energy of a system in terms of specific interactions. Implications fot theoretical and experimental studies. J Mol Biol 240:167-176

47. Boresch S, Archontis G, Karplus M (1994) Free energy simulations: the meaning of the individual contributions from a component analysis. Proteins Struct Funct Bioinf 20:25-33

48. Volpon L, Osborne MJ, Topisirovic I, Siddiqui N, Borden KL (2006) Cap-free structure of eIF4E suggests a basis for conformational regulation by its ligands. EMBO J 25:5138-5149 
49. Rutkowska-Wlodarczyk I, Stepinski J, dadlez M, Darzynkiewicz E, Stolarski R, Niedzwiecka A (2008) Structural changes of eIF4E upon binding to the mRNA $5^{\prime}$ monomethylguanosine and trimethylguanosine cap. Biochemistry 47:2710-2720

50. Brown CJ, McNae I, Fischer P, Walkinshaw MD (2007) Crystallographic and mass spectrometric characterisation of eIF4E with $\mathrm{N}^{7}$-alkylated cap derivatives. J Mol Biol 372:7-15

51. Blachut-Okrasinska E, Bojarska E, Niedzwiecka A, Chlebicka L, Darzynkiewicz E, Stolarski R, Stepinski J, Antosiewicz JM (2000) Stopped-flow and Brownian dynamic studies of electrostatic effects in the kinetics of binding of 7-methyl-GpppG to the protein eIF4E. Eur Biophys J 29:487-498

52. Niedzwiecka A, Stepinski J, Antosiewicz JM, Darzynkiewicz E, Stolarski R (2007) Biophysical approach to studies of cap-eIF4E interaction by synthetic cap analogs. Meth Enzymol 430:209-245

53. Slepenkov SV, Darzynkiewicz E, Rhoads RE (2006) Stoppedflow kinetic analysis of eIF4E and phosphorylated eIF4E binding to cap analogs and capped oligoribonucleotides. J Biol Chem 281:14927-14938
54. Kuzmic P (1996) Program DYNAFIT for the analysis of enzyme kinetic data: Application to HIV protease. Anal Biochem 237:260-273

55. Zuberek J, Jemielity J, Jablonowska A, Stepinski J, Dadlez M, Stolarski R, darzynkiewicz E (2004) Influence of electric charge variation at residues 209 and 159 on the interaction of eIF4E with the mRNA 5' terminus. Biochemistry 43:5370-5379

56. Hodel AE, Gershon PD, Shi X, Wang S-M, Quiocho AA (1997) Specific protein recognition of an mRNA cap through its alkylated base. Nat Struct Biol 4:350-354

57. Fechter P, Brownlee GG (2005) Recognition of mRNA cap structures by viral and cellular proteins. J Gen Virol 86:1239-1249

58. Worch R, Jankowska-Anyszka M, Niedzwiecka A, Stepinski J, Mazza K, Darzynkiewicz E, Cusack S, Stolarski R (2009) Diverse role of three tyrosines in binding of the RNA 5' cap to the human nuclear cap binding complex. J Mol Biol 385:618-627

59. Worch R, Stolarski R (2008) Stacking efficienct and flexibility analysis of aromatic amino acids in cap-binding proteins. Proteins Struct Funct Bioinf 71:2026-2037 